\title{
Selectivity Control in Palladium Catalyzed Alcohol Oxidation Through Selective Blocking of Active Sites
}

Sebastiano Campisi, $\uparrow$ Davide Ferri, $\ddagger$ Alberto Villa, $\uparrow$ Wu Wang, \# Di Wang, $§$ Oliver Kröcher, $\uparrow \uparrow$ and Laura Prati*,†

† Dipartimento di Chimica, Università degli Studi di Milano, Via Golgi 19, I-20133 Milano, Italy

‡ Paul Scherrer Institut, $\mathrm{CH}-5232$ Villigen PSI, Switzerland

\# Institute of Nanotechnology, Karlsruhe Institute of Technology, Hermann-von-Helmholtz-Platz 1, D-76344

Eggenstein-Leopoldshafen, Germany

$\S$ Institute of Nanotechnology and Karlsruhe Nano Micro Facility, Karlsruhe Institute of Technology, Hermannvon-Helmholtz-Platz 1, D-76344 Eggenstein-Leopoldshafen, Germany

ๆ Ecole polytechnique fédérale de Lausanne (EPFL), Institute of Chemical Sciences and Engineering, $\mathrm{CH}-1015$ Lausanne, Switzerland

\section{Supporting Information}

*To whom correspondence should be addressed. Email: laura.prati@unimi.it, Tel.: +39 0250314357 
Figure S1. Operando ATR-IR spectra of (a) $5 \mathrm{wt} \% \mathrm{Pd} / \mathrm{Al}_{2} \mathrm{O}_{3}$ and (b) $5 \mathrm{wt} \% \mathrm{Pd}_{\mathrm{PVA}} / \mathrm{Al}_{2} \mathrm{O}_{3}$ under oxidative conditions following the dehydrogenation segment shown in Figure 2. Grey spectra are intermediate spectra taken at approximately similar times on stream. Conditions: $C_{\text {alcohol }}=20 \mathrm{mM} ; 4$ mg catalyst; cyclohexane solvent; $60^{\circ} \mathrm{C}$; liquid flow rate $=0.6 \mathrm{~mL} / \mathrm{min}$.
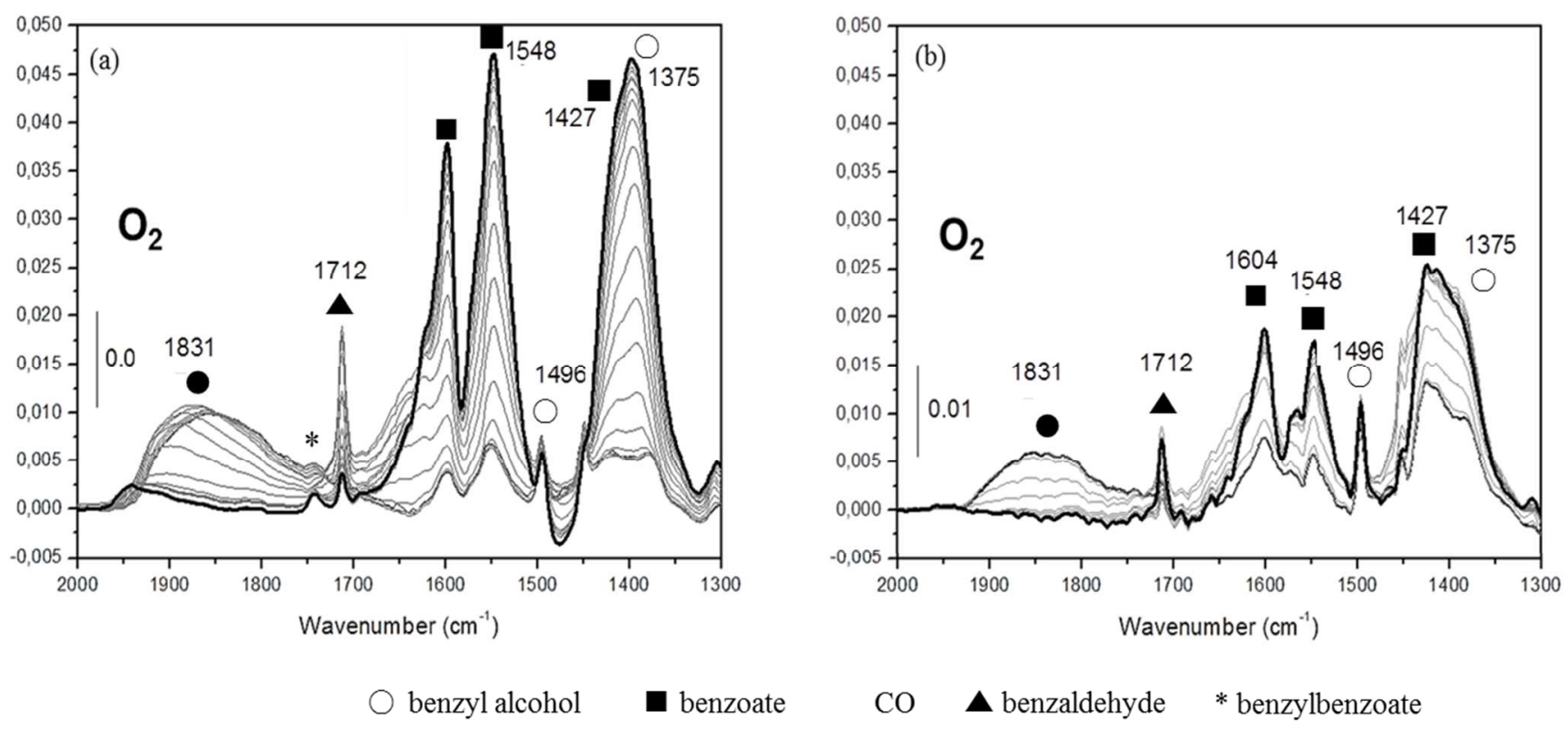

The selectivity improvement induced by the protective agent was also manifest in the presence of molecular oxygen (Fig. S1a and S1b, top panels). Under oxidative conditions, an increase of benzoate species on the catalyst surface was observed in both cases, while the $\mathrm{CO}$ signal quickly disappeared as a consequence of the $\mathrm{CO}$ removal by oxygen. In agreement with the batch reactor data revealing higher selectivity to benzoic acid for $5 \mathrm{wt} \% \mathrm{Pd} / \mathrm{Al}_{2} \mathrm{O}_{3}$ (Table 1), a greater amount of adsorbed benzoate was detected in the case of $5 \mathrm{wt} \% \mathrm{Pd} / \mathrm{Al}_{2} \mathrm{O}_{3}$ compared to $5 \mathrm{wt} \% \mathrm{Pd}_{\mathrm{PVA}} / \mathrm{Al}_{2} \mathrm{O}_{3}$. Furthermore, in the case of unprotected Pd NPs benzyl benzoate was also detected by ATR-IR spectroscopy (Figure 3 a, signal at $1741 \mathrm{~cm}^{-1}$ ), whereas it was absent in $5 \mathrm{wt} \% \mathrm{Pd}_{\mathrm{PVA}} / \mathrm{Al}_{2} \mathrm{O}_{3}$. Benzyl benzoate can tentatively form from dehydro-esterification of benzaldehyde and benzyl alcohol 
molecules adsorbed on adjacent sites. The argument of the site isolation effect induced by the capping agent that has been reported for $\mathrm{Au} / \mathrm{SiO}_{2}$ in the presence of polyvinylpyrrolidone (PVP) ${ }^{8}$ can be used to justify the absence of benzyl benzoate formation in PVA-protected Pd NPs.

Figure S2. Temporal evolution of selected signals observed during benzyl alcohol oxidation on $(a, b)$ $5 \mathrm{wt} \% \mathrm{Pd} / \mathrm{Al}_{2} \mathrm{O}_{3}$ and (c,d) $5 \mathrm{wt} \% \mathrm{Pd}_{\mathrm{PVA}} / \mathrm{Al}_{2} \mathrm{O}_{3}$. (a, c) ATR-IR signals of (o) benzyl alcohol (1496 $\left.\mathrm{cm}^{-1}\right),(\boldsymbol{\nabla})$ benzoate $\left(1531 \mathrm{~cm}^{-1}\right),(\mathbf{\Delta})$ benzaldehyde $\left(1712 \mathrm{~cm}^{-1}\right)$ and $(\bullet)$ CO $\left(1830 \mathrm{~cm}^{-1}\right) .(\mathrm{b}, \mathrm{d})$ FTIR signals of ( $(\circ)$ benzyl alcohol and $(\boldsymbol{\Delta})$ benzaldehyde.

a)

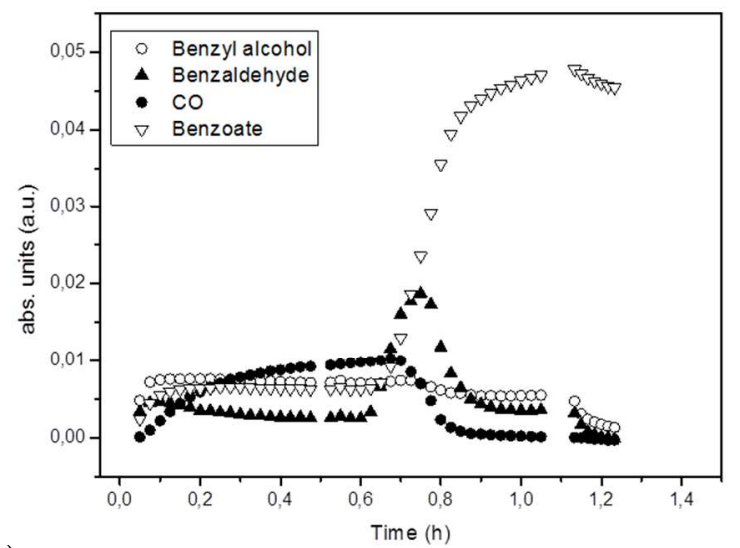

b)

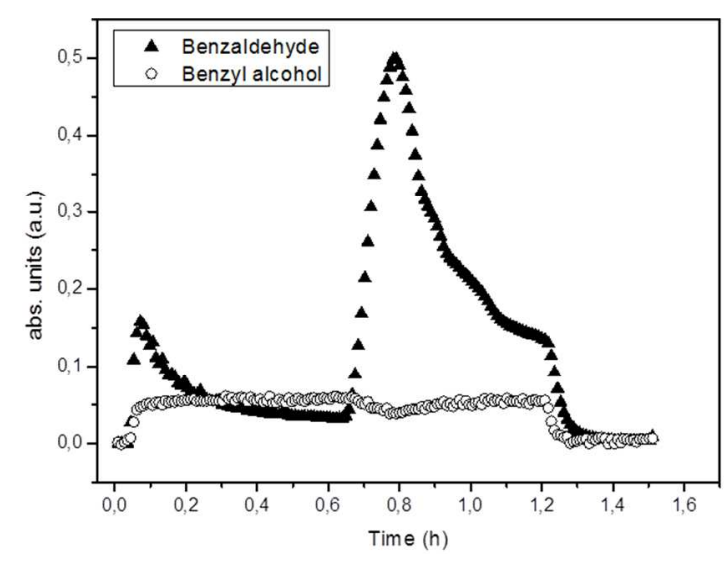

c)

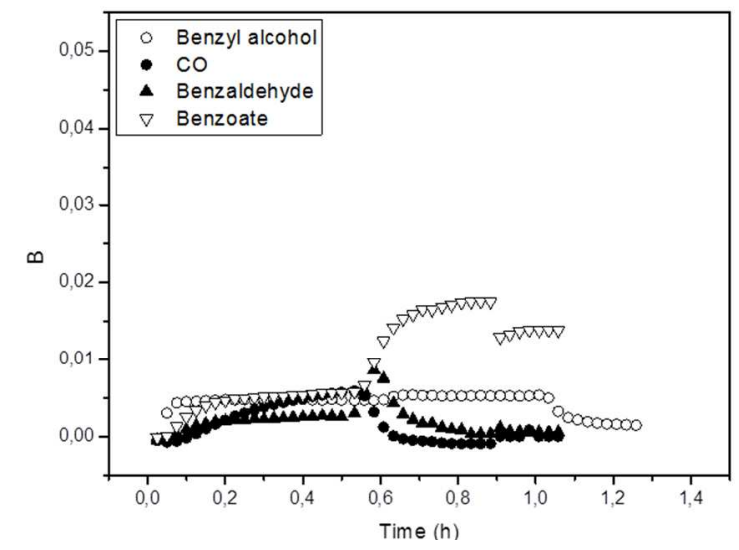

d)

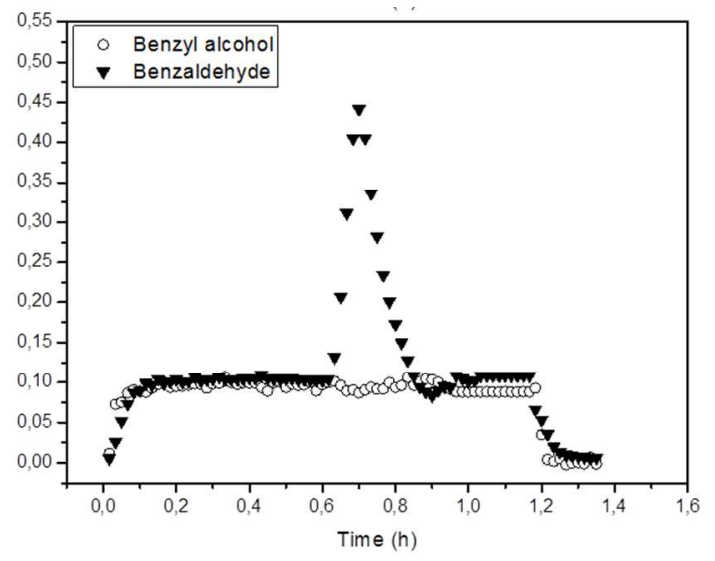

